\title{
Small bowel volvulus (SBV) in Northcentral Ethiopia
}

\author{
Atalel Fentahun Awedew ${ }^{1 *}$ D, Woldemariam Beka Belay ${ }^{2}$, Bedemariam Tadesse Amsalu ${ }^{3}$ and \\ Dawit Zerihun Yalewu ${ }^{3}$
}

\begin{abstract}
Background: Small bowel volvulus (SBV) is a benign gastrointestinal surgical condition in which there is a torsion of all or parts of a segment of small bowel on its mesenteric axis. It has been contributed significant burden of surgical emergency as cause of small bowel obstruction in developing countries. The main objective this study was to explore clinical and epidemiological profile of Small bowel volvulus in Northcentral Ethiopia.
\end{abstract}

Method: The study was conducted at Debre Tabor General Hospital, South Gondar in Northcentral Ethiopia. The medical records of patients with a discharge diagnosis of small bowel volvulus were reviewed. The patients were seen for a 4-year period from Jan1, 2016-Dec31, 2019. The study was hospital-based retrospective cross-sectional and data were collected with a standardized structure questioner tool. The collected data checked for any inconsistency, code, and enter SPSS version 23 for data processing and analysis. Descriptive analyses were represented as frequency, percent, mean \pm standard deviation for normal distribution, and Median \pm Interquartile range for skewed data. Cross tabulation analysis was done for risk factors contributed for mortality and morbidity of SBV.

Result: There were 148 patients with Small bowel volvulus as a cause of small bowel obstruction was admitted within 4 years. The annual occurrence rate was 35 cases per year. It represented $59 \%$ of small bowel obstruction and $36.3 \%$ of bowel obstruction. The majority were males $(N=125,84.5 \%)$ and females were $(N=23,15.5 \%)$. The age ranged from 15 to 78 years. The mean age was $41.14 \pm(S D=15.4)$. The most common clinical presentation was abdominal pain $98 \%$ and vomiting $91.2 \%$. The median time of hospital stay was 5 days $( \pm I Q R=2)$. The mean duration of illness before hospital admission was 2 days $( \pm S D=1.4)$ and median was 1 day $( \pm I Q R=2)$. The morbidity rate was $5.4 \%(N=8)$ and the mortality rate was $3.4 \%(N=5)$.

Conclusion: Annual occurrence of SBV was 37 cases per year. The prevalence of SBV was 59\% of small bowel obstruction and $36.3 \%$ of bowel obstruction respectively.

Keywords: Small bowel volvulus, Small bowel obstruction, Ethiopia, Debre Tabor

\section{Background}

The origin of the word volvulus is derived from the Latin word "volvere" which means turn or roll [1]. Small bowel volvulus $(\mathrm{SBV})$ is a benign gastrointestinal surgical condition in which there is a torsion of all or parts of a

\footnotetext{
* Correspondence: atalelfentahun27@gmail.com

1 Department of Surgery, Addis Ababa University, Addis Ababa, Ethiopia

Full list of author information is available at the end of the article
}

segment of small bowel on its mesenteric axis [2]. Small bowel volvulus is a rare cause of surgical emergency in the western and the USA while it is commonly found in Africa, India, and Iran [3]. Small bowel volvulus can be Neonatorm volvulus, primary or secondary according to the cause. The mechanism and underlying cause of primary SBV has not been well illustrated but the presumed factors include unusual mobility of small bowel,

(c) The Author(s). 2020 Open Access This article is licensed under a Creative Commons Attribution 4.0 International License, which permits use, sharing, adaptation, distribution and reproduction in any medium or format, as long as you give appropriate credit to the original author(s) and the source, provide a link to the Creative Commons licence, and indicate if changes were made. The images or other third party material in this article are included in the article's Creative Commons licence, unless indicated otherwise in a credit line to the material. If material is not included in the article's Creative Commons licence and your intended use is not permitted by statutory regulation or exceeds the permitted use, you will need to obtain permission directly from the copyright holder. To view a copy of this licence, visit http://creativecommons.org/licenses/by/4.0/ The Creative Commons Public Domain Dedication waiver (http://creativecommons.org/publicdomain/zero/1.0/) applies to the data made available in this article, unless otherwise stated in a credit line to the data. 
laxity of abdominal wall, physical exercise, absence of mesenteric fat, constipation or diarrhea, and the unusual length of small bowel segment [2-5]. Secondary SBV occurs in the presence of acquired underlying conditions such as post-op adhesion, tumors, pregnancy, diverticular disease, and bands [2] while Neonatorm volvulus is due to malrotation of bowel and defective fixation of mesentery [3]. Small bowel volvulus is a rare cause of mechanical small bowel obstruction. The incidence rate of SBV is high (24-60per 100,000populations) in Africa, Asia and Middle Eastern while low (1.7-5.7 per 100, 000populations) in western [6]. The overall mortality rate of SBV varies from 10 to $38 \%$, viable bowel 3-13\% in western and $20-25 \%$ in Africa and Indian. The mortality rate of gangrenous bowel has been reported in a range of $20-100 \%$ [7].

\section{Methods}

\section{Study area, period and design}

The study was conducted at Debre Tabor General Hospital, South Gondar in Northcentral Ethiopia. The medical records of patients with a discharge diagnosis of small bowel volvulus were reviewed. The patients were seen for a 4-year period from Jan1, 2016-Dec31, 2019. The study was hospital-based retrospective crosssectional and data were collected with a standardized structure questioner tool. The Question tool contained demography, clinical presentation, and duration of illness, procedures and intraoperative findings, postoperative complications, and management outcome. All patients from age 15 years and above with clinical or/ and radiological diagnosis of Small bowel volvulus which managed with conservatively and /or operatively or died due to confirmed Small bowel volvulus was included while paralytic Ileus (functional obstruction) and age below 15 years were excluded from the study. The hospital provides clinical service for approximately 900 inpatient and 80,000 outpatients in a year that comes from the catchment area of the population around 3.5 million.

\section{Data collection and analysis}

Data collected with a structured questionnaire that is developed by the English language and translated to the Amharic language. The tool was prepared after reviewed different literature and pretested before data collection. The collected data checked for any inconsistency, code, and enter SPSS version 23 for data processing and analysis. Normal distribution was evaluated with the Q-Q plot test and histogram diagram. Descriptive analyses were represented as frequency, percent; mean \pm standard deviation for normal distribution, and median \pm interquartile range for skewed data. Cross tabulation analysis was done for risk factors contributed for mortality and morbidity of SBV.

\section{Ethical consideration}

Ethical Review Committee of Debretabor University was approved and collection started after approval of the proposal. The confidentiality and privacy of patients maintained during data collection. The data collected retrospectively from the medical chart and consent from patients is not needed

\section{Results}

There were 148 patients with small bowel volvulus as a cause of small bowel obstruction was admitted within 4 years. It represented $59 \%$ of small bowel obstruction and $36.3 \%$ of bowel obstruction. The majority of SBV were males $(N=125,84.5 \%)$ and females were $(N=23$, $15.5 \%)$. The majority of SBV patients were rural residents $(N=121,81.8 \%)$ and urban residents were $(N=27$, $18.2 \%)$. The age ranged from 15 to 78 years. The mean age was 41.14 years $\pm(S D=15.4)$ (Table 1$)$.

The most common clinical presentation was abdominal pain $98 \%$ and vomiting $91.2 \%$. Most of the patients presented within $48 \mathrm{~h}(67.6 \%)$ and $48-72 \mathrm{~h}(19.6 \%)$. The mean of hospital stay was 5.3 days $( \pm \mathrm{SD}=2.9)$ and ranged from $1-18$ days. The median time of hospital stay was 5 days $( \pm I Q R=2)$. The mean duration of illness before hospital admission was 2 days $( \pm \mathrm{SD}=1.4)$ and median was 1 day $( \pm I Q R=2)$. Majority of the patient respond for conservative treatment with NPO, NGT decompression and fluid resuscitation (43.2\%). The most common procedure for non-respond for conservative measures were derotation and milking (DAM) for 39.9\% and primary resection and anastomosis for $16.2 \%$ (Table 2). The overall morbidity rate was $5.4 \%$ $(N=8)$ and the mortality rate was $3.4 \%(N=5)$ (Table 2 \& 3). Wound infection was found as most complication. The morbidity rate for patients who had undergone surgery was $9.6 \%$ and the mortality rate was $6 \%$.

Table 1 The Demographic and Characteristics of the Patients Small bowel volvulus in Debre Tabor Hospital, Northcentral Ethiopia, 2020

\begin{tabular}{llll}
\hline Item & & Frequency(N) & Proportion (\%) \\
\hline Age & $\mathbf{1 5 - 2 5}$ & 28 & 18.9 \\
$\mathbf{N = 1 4 8}$ & $\mathbf{2 6 - 3 5}$ & 34 & 23.0 \\
& $\mathbf{3 6 - 4 5}$ & 33 & 22.3 \\
& $\mathbf{4 6 - 5 5}$ & 29 & 19.6 \\
& $\mathbf{5 6 - 6 5}$ & 15 & 10.1 \\
& $>\mathbf{6 6}$ & 9 & 6.1 \\
SeX & $\mathbf{M}$ & 125 & 84.5 \\
$\boldsymbol{N}=\mathbf{1 4 8}$ & Female & 23 & 15.5 \\
Residence & Rural & 121 & 81.8 \\
$\boldsymbol{N}=\mathbf{1 4 8}$ & Urban & 27 & 18.2 \\
\hline
\end{tabular}


Table 2 The Clinical presentation of Patients with Small bowel volvulus in Debre Tabor Hospital, Northcentral Ethiopia, 2020

\begin{tabular}{|c|c|c|c|}
\hline Item & & Frequency $(N)$ & Proportion(\%) \\
\hline \multirow[t]{4}{*}{ Clinical Symptoms } & Abdominal Pain & 145 & 98 \\
\hline & Vomiting & 135 & 91.2 \\
\hline & Abdominal Distention & 91 & 61.5 \\
\hline & Constipation & 100 & 67.6 \\
\hline \multirow[t]{5}{*}{ Clinical Sign } & Drainage Vital sign & 19 & 12.8 \\
\hline & Abdominal Tenderness & 126 & 85.1 \\
\hline & Hypo/Hyperactive bowel sound & 71 & 48 \\
\hline & Visible peristalsis & 96 & 64.9 \\
\hline & Hyper tympanic & 123 & 83.1 \\
\hline \multirow[t]{3}{*}{ Mode Treatment } & Emergency & 83 & 56.1 \\
\hline & Conservative & 64 & 43.2 \\
\hline & Death before procedure & 1 & 0.7 \\
\hline \multirow[t]{4}{*}{ Procedure } & Derotation and Milking & 59 & 39.9 \\
\hline & Primary resection and anastomosis & 24 & 16.2 \\
\hline & Conservative & 64 & 43.2 \\
\hline & Death before procedure & 1 & 0.7 \\
\hline
\end{tabular}

Cross tabulation analysis showed morbidity rate of SBV was more likely female $8.7 \%$ vs $4.8 \%$, common in age $>40$ years $5.8 \%$ vs $5.1 \%$, urban $7.4 \%$ vs. $5 \%$, Hospital stay $>7$ days $24 \% \mathrm{vs} 1.6 \%$, patients presented $72-96 \mathrm{~h}$. $12.5 \%$,as compared less than $48 \mathrm{~h} 5 \%$, gangrenous SBV $20 \%$ vs. $2.4 \%$,emergency procedure $\quad 9.6 \%$ vs0\% conservative and primary resection and analysis $16 \%$ vs derotation and milking (DAM).

Cross tabulation analysis showed mortality of SBV was more likely common in age $<40$ years $3.8 \% \mathrm{vs} 2.9 \%$, urban $3.7 \%$ vs.3.3\%, hospital stay $>7$ days $4 \%$ vs $3.3 \%$, patients presented above $97 \mathrm{~h} 18.2 \%$ as compared less than $48 \mathrm{~h}$

Table 3 The Pattern and outcomes of Patients with Small bowel volvulus in Debre Tabor Hospital, Northcentral Ethiopia, 2020

\begin{tabular}{|c|c|c|c|}
\hline Item & & Frequency $(N)$ & Proportion(\%) \\
\hline \multirow[t]{2}{*}{$S V$} & Simple SBV & 123 & 83.1 \\
\hline & Gangrenous SBV & 25 & 16.9 \\
\hline \multirow[t]{2}{*}{ Type of SBV } & Primary & 148 & 100 \\
\hline & Secondary & 0 & 0 \\
\hline \multirow[t]{4}{*}{ Outcome } & Improved & 132 & 89.2 \\
\hline & Morbidity & 8 & 5.4 \\
\hline & Leave against medical advice & 2 & 1.4 \\
\hline & Mortality & 5 & 3.4 \\
\hline \multirow[t]{4}{*}{ Duration of illness before hospital visits } & $<48 \mathrm{~h}$ & 100 & 67.6 \\
\hline & $48-72 \mathrm{~h}$ & 29 & 19.6 \\
\hline & $72-96 h$ & 8 & 5.4 \\
\hline & $>96 \mathrm{~h}$ & 11 & 7.4 \\
\hline \multirow{2}{*}{$\begin{array}{l}\text { Hospital stay } \\
N=148\end{array}$} & $<=7$ days & 123 & 83.1 \\
\hline & $>7$ days & 25 & 16.9 \\
\hline \multirow{5}{*}{$\begin{array}{l}\text { Morbidity } \\
N=8\end{array}$} & Wound Infection & 4 & 2.7 \\
\hline & Anastomosis Leak & 1 & 0.7 \\
\hline & Fistula & 1 & 0.7 \\
\hline & Paralytic illness & 1 & 0.7 \\
\hline & others & 1 & 0.7 \\
\hline
\end{tabular}


$2 \%$, gangrenous SBV 8\%vs.2.4\%,emergency procedure 6\% vs0\% conservative and derotation and milking (DAM)7\%vs.4\% in primary resection and analysis.

\section{Discussion}

Small bowel volvulus is a rare cause of small bowel obstruction in the western and the USA $[1,2,8]$. The incidence rate of SBV is high (24-60 per 100, 000populations) in Africa, Asia and Middle Eastern while low (1.7-5.7 per 100,000populations) in western [6]. Annual occurrence in the USA and Europe is quite low compared with that in Africa, Middle East countries, and Asian [2, 3, 7, 9-11] (Table 4). A 57-years data review in the USA found that annual occurrences of SBV was 0.6 case per year and SBV accounted for $6.9 \%$ of all bowel obstruction [7]. Welch CE 1958 reported that the prevalence reduction from 6.9 to $3.3 \%$ in the period of 1930-1958 in the USA [12] .A. Roggo and L. W. Ottinger (1992) at the Massachusetts General Hospital over 10 years reported those 35 small bowel volvulus were treated which represented $1.7 \%$ of bowel obstructions and $4 \%$ of small bowel obstructions [7]. Vaez-Zadeh et al. (1969) reported the incidence of small bowel volvulus in Iran was 19.6 and $41 \%$ in bowel obstruction and small bowel obstruction respectively [2].

A series of research done in Ethiopia reported that small bowel volvulus accounted sizable portion of bowel obstruction; Tegegne A. 1992(18.3\%) [13], Lintjorn B.1981et al (38.6\%) [14], M. Demissie 2001(41.7\%) [2], Gizaw TA.et al. 2016, (36.4\%) [15], Soressa U.et al. 2016, (30.3\%) [16]. I.O.McDonald et al. 1980 reported more than $50 \%$ of bowel obstruction due to Small bowel volvulus in Nepal [5]. This great discrepancy of the prevalence of small bowel volvulus may due to dietary factors that when a bulky bolus of food entered the proximal jejunum, that loop felt down into pelvis and causing empty distal bowel to rise into a right upper quadrant. Rapid emptying of the stomach and diaphragm makes the distal bowel spread across the left upper quadrant. As this distal loop themselves filed up would fall into left quadrat completing $360^{\circ}$ twists [3]. Primary SBV is more common in developing countries while secondary SBV is more in developed countries. Frazee RC et.al 1988 (UK) and A. Roggo and L. W. Ottinger 1992(USA) noted that secondary SBV accounted for $89 \% \& 86 \%$ of SBV respectively [7, 9] (Table 4). A Research done by Vaez-Zadeh et al. 1969(Iran), M. Demssie 2001(Ethiopia) and De Souza LJ1976 (Uganda) showed that primary SBV accounted 80, 94.9 and $100 \%$ of SBV respectively $[2,3,11]$ (Table 4). We found that primary SBV accounted $100 \%$ of SBV. The presumed risk factors in different literature were hypermobility of bowel gut, hypermobility of mesentery, and bulky and poorly digestible diet taken at long intervals [2, 7, 9, 17].

The speculation was some populations have long mesenteric and short roots of mesentery which would allow abnormal mobility of whole or segment of the small bowel. Diet and pattern of feeding is also the most relevant risk factor for occurrences of primary SBV. The Abrupt change of dietary habit of ingestion of a single large amount and bulky food after a long interval of fasting or empty of bowel may induce forceful bowel peristalsis, resulting in SBV $[2,7,9,17]$. Secondary small bowel volvulus occurs in the presence of underlying identified predisposed conditions. It is mainly seen in bands, post-op adhesion, malrotation, or midgut nonrotation in newborn and young children and a gastrointestinal infestation of the parasite. The prevalence of secondary SBV is more common in western, constituting a 70-90\% of case [7].

The prevalence of primary SBV is more common in children and young while secondary SBV is dominantly

Table 4 Literature Review

\begin{tabular}{|c|c|c|c|c|c|c|}
\hline Authors & $\begin{array}{l}\text { Atalel F. } \\
\text { Current study }\end{array}$ & M. Demssie & Roggo & Frazee & Welchi & Veaz-Zadah \\
\hline Study Place & DGH, Ethiopia & Southern, Ethiopia & Bosten & Rochester MN & Glasgow UK & Iran \\
\hline Study period & Jan1,2016-Dec31, 2019 & June 1992toMay 1996 & 1980-1990 & 1975-1984 & 1965-1980 & 1962-1965 \\
\hline Duration Years & 4 & 4 & 10 & 10 & 15 & 5 \\
\hline No of patients & 148 & 98 & 35 & 57 & 53 & 41 \\
\hline Annual occurs & 37 & 24.5 & 3.5 & 5.7 & 3.5 & 8.2 \\
\hline Male to Female & $5.4: 1$ & $8.8: 1$ & $1: 1.2$ & $1: 1$ & $1: 1.12$ & $9.25: 1$ \\
\hline Mean age & 41.14 & 34.1 & 67 & 59 & 54 & 42 \\
\hline Primary SBV(\% & 100 & 94.9 & 14 & 11 & 30 & 80 \\
\hline Secondary SBV ${ }^{*} \%$ & 0 & 5.1 & 86 & 89 & 70 & 20 \\
\hline Gangrenous SBV(\% & 16.9 & 28.7 & 46 & 49 & 43 & - \\
\hline Overall Mortality & 3.4 & 13.3 & 9 & 12 & 28 & 15 \\
\hline Viable SBV & 2.4 & 8.3 & 0 & 3 & 11 & - \\
\hline Gangrenous SBV & 8 & 25.9 & 17 & 21 & 47 & - \\
\hline
\end{tabular}


in old age. A study conducted in the different areas stated that the mean age was 67 years in the USA,34 years in Ethiopia, 42 years in Iran, 59 years in the UK (2, $3,7,13$ ] (Table 4). We found that the mean age was 42 years. The incidence of SBV is a male predominance, particularly in developing countries. The research described that male to female proportion 1:1.2 in USA, 1: 1.12 in UK, 9.25:1 in Iran, 8.8:1 in Ethiopia [2, 3, 7, 9]. We found similar results on the male to female proportion 5.4:1(Table 4). The exact cause of sex discrepancy is not well-illustrated but possible reasons suggested that spacious female pelvic area allowed a greater possibility of spontaneous reduction of volvulus, females have a lax abdominal wall due to childbearing, doing less heavy and prolonged exercise and more obese [2, 3, 7]. Our finding noted that SBV was more common in rural resident due to more childbearing, doing less heavy, long time fasting and higher fiber diet.

The literature review summarized the common complaints of SBV abdominal pain 94-100\%, vomiting 83$100 \%$, and abdominal distention $55-100 \%$ [7]. Our result identified the common clinical complaints of SBV similar to the previous review; abdominal pain 98\%, vomiting 92.1\% and distention $61.5 \%$ and frequent physical findings were abdominal tenderness $85.1 \%$ and visible peristalsis $64.9 \%$.

SBV has been contributing a significant burden in mortality and morbidity especially when the bowel becomes gangrenous, ischemic, and develops peritonitis. The prevalence of gangrenous SBV depends on the health-seeking behavior of the community, access to a health facility, early diagnosis, and economy of the patients. The incidence of gangrenous SBV was 28.7 in Ethiopia, $46 \%$ in the USA, and $43 \%$ in the UK $[2,7,9]$.

Our study found that the incidence of gangrenous SBV $16.9 \%$. This difference study conducted in the USA and UK was in the early 1950s and currently increases access to surgical investigation modality decreasing the incidence of gangrenous SBV.

SBV had a high mortality rate but currently mortality due to SBV decreasing due to the advance of surgical health, investigation, and early diagnosis. Overall mortality rate reported 26\% in Nepal,13.3\% in Ethiopia,28\% in UK, $9 \%$ in USA and $15 \%$ in Iran $[2,3,5,7,9]$. Our finding was lowered compared with the previous study (3.4\%).

\section{Conclusion}

Annual occurrence of SBV was 37 cases per year. The prevalence of SBV was $59 \%$ of small bowel obstruction and $36.3 \%$ of bowel obstruction respectively. It had low morbidity and mortality rate (5.4 \&3.4\% respectively). The majority of SBV were respond with conservative treatment with NPO, NGT decompression and resuscitation (43.2\%).

\section{Abbreviations}

COR: Crude Odd Ratio; DAM: Derotation and Milking; IQR: Inter Quartile Range; NGT: Nasogastric tube; NPO: Nill per os; OR: Odd Ratio; SBO: Small bowel obstruction; SBV: Small Bowel volvulus; SD: Standard deviation; SPSS: Statistical package for Social Science; UK: United Kingdom; USA: United States of America

\section{Acknowledgments}

Not applicable.

\section{Authors' contributions}

Conceptualization: AF. Data collection and Methodology development: AF BT WB DZ. Software: AF BT. Data analysis: AF BT. Manuscript Draft: AF.

Manuscript review and editing; AF BT WB DZ. All authors have read and approved the manuscript.

\section{Funding}

No funding given for this study.

\section{Availability of data and materials}

The datasets used and/or analyzed during the current study available from corresponding author on reasonable request.

\section{Ethics approval and consent to participate}

Ethical Review Committee of Debretabor University approved the ethical issue of this study and official permission to undertaken the study obtained from Debre Tabor General Hospital. The confidentiality and privacy of patients maintained during data collection. The data collected retrospectively from medical chart and consent from patients is not needed.

\section{Consent for publication}

Not applicable.

\section{Competing interests}

Authors declare that they have no competing interests.

\section{Author details}

'Department of Surgery, Addis Ababa University, Addis Ababa, Ethiopia.

${ }^{2}$ Department of Surgery, Debre tabor Hospital, Debre Tabor, Ethiopia.

${ }^{3}$ Department of Surgery, Debre Tabor University, Debre Tabor, Ethiopia.

Received: 7 June 2020 Accepted: 27 September 2020

Published online: 02 October 2020

References

1. Gingold D, Murrell Z. Management of Colonic Volvulus. Clin Colon Rectal Surg. 2012;25:236-44.

2. Demissie M. Small intestinal volvulus in Southern Ethiopia. East Afr Med J. 2001;78(4):208-11. https://doi.org/10.4314/eamj.v78i4.9065. PMID: 12002073.

3. Vaez-Zadeh K, Dutz W, Nowrooz-Zadeh M. Volvulus of the small intestine in adults: a study of predisposing factors. Ann Surg. 1969;169(2):265-71. https://doi.org/10.1097/00000658-196902000-00014.

4. Warambo MW. Acute volvulus of the small intestine. East Afr MedJ. 1971;48: 209-12.

5. McDonald IO, Hawker DB. Small bowel volvulus - the commonest abdominal emergency in Nepal. Bristol Med Chir J. 1980;95(355-356):4-8. PMID: 7343058; PMCID: PMC5117399.

6. Imuagwu O, Deans GT. Small bowel volvulus: a review. J R Coll Surg Edinb. 1999:44:150-5.

7. Roggo A, Ottinger LW. Acute small bowel volvulus in adults. A sporadic form of strangulating intestinal obstruction. Ann Surg. 1992;216(2):135-41. https://doi.org/10.1097/00000658-199208000-00003.

8. Li X, Zhang J, Li B, Yi D, Zhang C, Sun N, et al. Diagnosis, treatment and prognosis of small bowel volvulus in adults: A monocentric summary of a rare small intestinal obstruction. PLoS ONE. 2017:12(4):e0175866. https://doi. org/10.1371/journal.pone.0175866.

9. Frazee RC, Mucha P, Farnell MB, van Heerden JA. Volvulus of the small intestine. Ann Surg. 1988;208:565-8.

10. Welch GH, Anderson JR. Volvulus of the small intestine in adults. World J Surg. 1986;10:496-9.

11. De Souza L. Volvulus of the small bowel. Br Med J. 1976;1:1055-6.

12. Welch CE. Intestinal obstruction. Chicago: Year Book Publishers; 1958. p. 14. 
13. Tegegne A. Small intestinal volvulus in adults of Gonder region, northwestern Ethiopia. Ethiop Med J. 1992;30:211 1-7.

14. Lintjorn B, Breivik K. And Lendes. Intestinal volvulus in Sidamo, southern Ethiopia. Easr Afr Med J. 1981;58:208-11.

15. Ayenew Z, Gizaw AT, Workneh D, Fentahun N. Outcome of non-traumatic surgical acute abdomen in Nekemte referral hospital Southwest Ethiopia: a retrospective cross-sectional study. Surgery Curr Res. 2016;7:282. https://doi. org/10.4172/2161-1076.1000282.

16. Soressa U, Mamo A, Hiko D, Fentahun N. Prevalence, causes and management outcome of intestinal obstruction in Adama hospital, Ethiopia. BMC Surg. 2016;16:38

17. Barabde M, Tiwari S, Lavankar V. Small bowel volvulus: a rare twist in an adult. Int J Sci Rep. 2016;2(2):44-7.

\section{Publisher's Note}

Springer Nature remains neutral with regard to jurisdictional claims in published maps and institutional affiliations.

Ready to submit your research? Choose BMC and benefit from:

- fast, convenient online submission

- thorough peer review by experienced researchers in your field

- rapid publication on acceptance

- support for research data, including large and complex data types

- gold Open Access which fosters wider collaboration and increased citations

- maximum visibility for your research: over $100 \mathrm{M}$ website views per year

At BMC, research is always in progress.

Learn more biomedcentral.com/submissions 